\title{
Guided bone regeneration and abutment connection augment the buccal soft tissue contour: 3-year results of a prospective comparative clinical study
}

Benic, Goran I ; Ge, Yanjun ; Gallucci, German O ; Jung, Ronald E ; Schneider, David ; Hämmerle, Christoph H F

Abstract: AIM: To test whether implant placement with simultaneous guided bone regeneration (GBR) differs from implant placement without GBR regarding the change in marginal mucosal contour. MATERIALS AND METHODS: In 28 patients, single implants were placed $>4$ months after tooth extraction. Eighteen implants were completely surrounded by native bone, and no bone augmentation was performed. At 10 implant sites, bone defects and thin bone plates were grafted with deproteinized bovine-derived bone mineral and covered with collagen membrane. Impressions were taken prior to implant placement (baseline), at 3 months before abutment connection, at 6 months immediately after crown insertion, at 1 year, and at 3 years. Models were optically scanned and 3D images were superimposed for the evaluation of mucosal contour changes at the mid-buccal aspect. The nonparametric Mann-Whitney U-test was applied to detect differences. RESULTS: From baseline to 6 months, horizontal contour change at the level 1 and $2 \mathrm{~mm}$ apical to the mucosal margin measured $0.65 \pm 0.74$ $\mathrm{mm}$ and $0.55 \pm 0.56 \mathrm{~mm}$ at sites without GBR, and $1.92 \pm 0.87 \mathrm{~mm}$ and $1.76 \pm 0.70 \mathrm{~mm}$ at sites with $\mathrm{GBR}(\mathrm{P}<0.05)$. In the period from baseline to 1 year, the corresponding values amounted to $0.81 \pm 0.67 \mathrm{~mm}$ and $0.60 \pm 0.55 \mathrm{~mm}$ in the group without GBR, and to $1.81 \pm 0.86 \mathrm{~mm}$ and $1.37 \pm 0.62 \mathrm{~mm}$ in the group with $\mathrm{GBR}(\mathrm{P}<0.05)$. From baseline to 6 months, mucosal margin moved $0.16 \pm 0.49 \mathrm{~mm}$ in the coronal direction in the group without GBR and 0.82 $\pm 0.65 \mathrm{~mm}$ in the group with GBR $(\mathrm{P}<0.05)$. In the period from baseline to 1 year, vertical change of mucosal margin amounted to $0.64 \pm 0.54 \mathrm{~mm}$ in the group without GBR and to $1.17 \pm 0.53 \mathrm{~mm}$ in the GBR group $(\mathrm{P}<0.05)$. From 1 to 3 years, the mucosal contours remained stable. CONCLUSIONS: Implant placement with simultaneous GBR resulted in more gain of buccal soft tissue contour in comparison with implant placement without GBR. Abutment connection increased the contour of the marginal mucosa at the augmented and the nonaugmented sites. GBR procedure contributed more to the contour gain than did the abutment connection. The augmented and the nonaugmented ridges exhibited stable peri-implant mucosal contour over a 3-year period.

DOI: https://doi.org/10.1111/clr.12786

Posted at the Zurich Open Repository and Archive, University of Zurich

ZORA URL: https://doi.org/10.5167/uzh-123473

Journal Article

Accepted Version

Originally published at:

Benic, Goran I; Ge, Yanjun; Gallucci, German O; Jung, Ronald E; Schneider, David; Hämmerle, Christoph H F (2017). Guided bone regeneration and abutment connection augment the buccal soft tissue contour: 3-year results of a prospective comparative clinical study. Clinical Oral Implants Research, 28(2):219-225.

DOI: https://doi.org/10.1111/clr.12786 


\section{Guided bone regeneration and abutment connection augment the buccal soft tissue contour: 3-year results of a prospective comparative clinical study}

\section{Goran I. Benic ${ }^{1}$, Yanjun $\mathrm{Ge}^{2}$, German O. Gallucci ${ }^{3}$, Ronald E. Jung ${ }^{1}$, David Schneider ${ }^{1}$, Christoph H.F. Hämmerle ${ }^{1}$}

1: Clinic of Fixed and Removable Prosthodontics and Dental Material Science, Center of Dental Medicine, University of Zurich, Zurich, Switzerland

2: Department of Prosthodontics, Hospital of Stomatology, Peking University, Beijing, P. R. of China

3: Department of Restorative Dentistry and Biomaterials Sciences, Harvard School of Dental Medicine, Boston, MA, USA

Running title: Buccal contour change after GBR vs. no GBR

Key words: dental implant, bone, regeneration, guided bone regeneration, GBR, bone substitute, abutment connection, contour, mucosa, soft tissue, volume, optical, scan, human, clinical

Address for correspondence:

Dr. Goran I. Benic

Clinic of Fixed and Removable Prosthodontics and Dental Material Science

Center of Dental Medicine

University of Zurich

Plattenstrasse 11

$\mathrm{CH}-8032$ Zurich

E-mail: goran.benic@zzm.uzh.ch

Tel: +41446343260

Fax: +41446344305 


\section{Abstract}

Aim: To test whether implant placement with simultaneous guided bone regeneration (GBR) differs from implant placement without GBR regarding the change in marginal mucosa contour.

Material and methods: In 28 patients, single implants were placed $>4$ months after tooth extraction. Eighteen implants were completely surrounded by native bone and no bone augmentation was performed. At 10 implant sites, bone defects and thin bone plates were grafted with deproteinized bovine-derived bone mineral and covered with collagen membrane. Impressions were taken prior to implant placement (baseline), at 3 months before abutment connection, at 6 months immediately after crown insertion, at 1 year, and 3 years. Models were optically scanned and 3D images were superimposed for the evaluation of mucosa contour changes at the mid-buccal aspect. The non-parametric Mann-Whitney test was applied to detect differences.

Results: From baseline to 6 months, horizontal contour change at the level 1 and 2 $\mathrm{mm}$ apical to the mucosal margin measured $0.65 \pm 0.74 \mathrm{~mm}$ and $0.55 \pm 0.56 \mathrm{~mm}$ at sites without GBR, and $1.92 \pm 0.87 \mathrm{~mm}$ and $1.76 \pm 0.70 \mathrm{~mm}$ at sites with $\mathrm{GBR}(P<0.05)$. In the period from baseline to 1 year, the corresponding values amounted to $0.81 \pm 0.67 \mathrm{~mm}$ and $0.60 \pm 0.55 \mathrm{~mm}$ in the group without GBR, and to $1.81 \pm 0.86 \mathrm{~mm}$ and $1.37 \pm 0.62 \mathrm{~mm}$ in the group with GBR $(P<0.05)$. From baseline to 6 months, mucosal margin moved $0.16 \pm 0.49 \mathrm{~mm}$ in the coronal direction in the group without GBR and $0.82 \pm 0.65 \mathrm{~mm}$ in the group with GBR $(P<0.05)$. In the period from baseline to 1 year, vertical change of mucosal margin amounted to $0.64 \pm 0.54 \mathrm{~mm}$ in the group without GBR and to $1.17 \pm 0.53 \mathrm{~mm}$ in the GBR group $(P<0.05)$. From 1 year to 3 years, the mucosal contours remained stable.

Conclusions: Implant placement with simultaneous GBR resulted in more gain of buccal soft tissue contour in comparison to implant placement without GBR. Abutment connection increased the contour of the marginal mucosa at the augmented and the nonaugmented sites. GBR procedure contributed more to the contour gain than did the abutment connection. The augmented and the non-augmented ridges exhibited stable peri-implant mucosal contour over a 3-year period. 


\section{Introduction}

Guided bone regeneration (GBR) is the most widely used and well-documented method used to augment bone in localized alveolar defects (Benic \& Hammerle 2014). The aim of GBR is to allow the placement of implants in prosthetically correct position and to increase the clinical success of dental implants through the resolution of peri-implant bone defects. In esthetically sensitive jaw regions, GBR is also applied to increase the buccal soft tissue contour to achieve a natural appearance of the peri-implant soft tissues.

There is a high level of clinical evidence that survival rates of implants placed simultaneously with, or after, GBR are similar to survival rates of implants placed into pristine bone (Donos et al. 2008, Hammerle et al. 2002, Jensen \& Terheyden 2009). However, very little evidence is available on the three-dimensional stability of the augmented hard tissue and on the influence of GBR on the short- and long-term mucosal contour changes (Benic \& Hammerle 2014, Lutz et al. 2015).

In a recent study, implants placed immediately into extraction sockets were assessed after 7 years by using cone beam computed tomography (Benic et al. 2012a). At implant placement, peri-implant defects were grafted with particulated deproteinized bovine-derived bone mineral (DBBM) and covered with a collagen membrane without over-augmenting the buccal bone plate. At the 7-year examination, at approximately one-third of the sites almost no buccal bone was radiographically detected, whereas, within the other implant sites, the buccal bone plate covered the entire rough implant surface. The lack of radiographically detectable buccal bone was associated with $1 \mathrm{~mm}$ more apical position of the mucosal margin. In another clinical study, peri-implant dehiscences at single implants were augmented with non-resorbable membranes and DBBM (Schneider et al. 2011). In the majority of patients, the gain of peri-implant tissue in the buccal direction was in the range from 1 to $1.5 \mathrm{~mm}$ and remained stable to a high degree within the first year after crown insertion. The GBR procedure contributed more to the volume gain than did the soft tissue grafting. Up to date, however, there have been no investigations that compared the implant sites augmented by GBR to the control sites without GBR. Therefore, the effect of GBR procedure on the peri-implant soft tissue contour remains not clearly understood.

The primary aim of the present prospective non-randomized study was to test whether implant placement in combination with GBR by using particulated DBBM and collagen membrane differs from implant placement without GBR regarding the change in the horizontal soft tissue contour. In addition, the influence of the abutment connection procedure on the mucosa contour was assessed. 


\section{Material and Methods}

The study was conducted at two centres (Clinic of Fixed and Removable Prosthodontics and Dental Material Science, Center of Dental Medicine, University of Zurich, Zurich, Switzerland and Department of Restorative Dentistry and Biomaterials Sciences, Harvard School of Dental Medicine, Boston, MA, USA). The clinical protocol was approved by the local ethical committees and informed consent was obtained from all the patients.

\section{Study population}

Twenty-eight patients with single-tooth gaps in the anterior or premolar region were included in this study. The patients participated at the randomized controlled trial that compared titanium $4.1 \mathrm{~mm}$-diameter implants to titanium-zirconium $3.3 \mathrm{~mm}$-diameter implants (Benic et al. 2013).

The subjects fulfilled the following inclusion criteria:

- $\geq 18$ years of age

- No active periodontal disease

- Full-mouth plaque score (FMPS) and full-mouth bleeding score (FMBS) $<25 \%$

- Need of an implant-supported crown at a single-tooth gap in regions 11-15, 2125, 31-35, 41-45 (FDI)

- Presence of mesial and distal natural teeth

- Implant placement $>4$ months after tooth extraction

- No need of soft tissue grafting

- Presence of baseline, 3-month, 6-month and 1-year plaster models

- Possibility of superimposition of the digitized plaster models

\section{Treatment procedures}

All the investigators participating in the study were experienced in implant placement and bone regeneration procedures. Prior to the study initiation, all participating investigators attended a calibration session to standardize the treatment procedures.

The implants were placed $>4$ months after tooth extraction. The implant placement surgery was performed under local anaesthesia. Sulcular incisions, a mid-crestal incision and, if needed, a vertical release incision were performed, and the mucoperiosteal flap was raised. The implant bed was prepared according to the manufacturer's instruction for the 
placement of Straumann ${ }^{\circledR}$ Bone Level implants (Straumann AG, Basel, Switzerland). All the implants were placed to allow a screw-retained crown on a straight abutment.

Based on the need of hard-tissue augmentation the implants were allocated to one of the following treatment groups:

- GBR group: Peri-implant bone dehiscences, fenestrations, infrabony defects measuring $>0.5 \mathrm{~mm}$ of width, and bone plates with $<0.5 \mathrm{~mm}$ of thickness were grafted with particulated DBBM (BioOss $^{\circledR}$ Spongiosa Granules; Geistlich Pharma AG, Wolhusen, Switzerland) and covered with a native collagen membrane (BioGide ${ }^{\circledR}$; Geistlich Pharma AG). DBBM was applied to cover the exposed implant surface and the remaining buccal bone plate (Figure 1).

- No GBR group: In the absence of bone defects or thin bone plates, no additional hard-tissue management was undertaken.

When necessary, periosteal release incision was performed to allow tension-free adaptation. Mucoperiostal flaps were sutured using ePTFE suture (Gore-Tex ${ }^{\circledR}$, Gore, Flagstaff, AZ, USA). All the implants healed in a submerged position.

The patients were instructed to rinse twice daily with $0.2 \%$ chlorhexidine-digluconate and analgesics were prescribed for the first 3 days. In cases of GBR, the patients underwent an antibiotic regimen for 5 days ( $3 \times 750 \mathrm{mg} /$ day amoxicillin). The sutures were removed after 1 week.

After 3 months, the abutment connection procedure was performed by means of midcrestal ridge incision and insertion healing abutments. The final metal-ceramic crown was inserted 6 months after implant placement. The patients were invited for the follow-up examination 1 and 3 years after implant placement (Figure 1).

\section{Soft tissue contour evaluation}

Partial jaw impressions with silicone material (President, Coltène, Altstätten, Switzerland) were taken: (1) at baseline immediately prior to implant placement, (2) at 3 months after implant placement just before abutment connection, (3) at 6 months immediately after insertion of definitive crown, (4) at 1 year, and (5) at 3 years. Prior to the insertion of definitive crown, (6) an impression of the buccal contour of the crown connected to the corresponding implant (crown-implant contour) was taken extraorally. 
The study models were cast using type IV dental stone (Quadro-Rock ${ }^{\circledR}$ plus, Picodent $^{\circledR}$, Germany) and optically scanned with (Imetric 3D GmbH, Courgenay, Switzeland) (Figure 2).

For the evaluation of mucosa contour changes, STL datasets were imported in the smop software (Swissmeda AG, Zurich, Switzerland) (Figure 3). The teeth surfaces in the baseline dataset were used as reference for the superimposition of the 3D images. The crown-implant contour was used for the determination of the implant axis. Bucco-oral crosssections through the implant axis were used for the measurements. All the measurements were performed by one blinded investigator.

The following mucosal changes were measured with reference to the baseline dataset:

- Horizontal contour change: distance between the mucosal contours at the level 1 $\mathrm{mm}$ and $2 \mathrm{~mm}$ apical to the crown-mucosa margin at crown insertion measured in a direction perpendicular to the implant axis

- Vertical change in mucosal margin: distance between the crown-mucosa margins measured in a direction parallel to the implant axis. The intersections of the crown-implant contour with the baseline and the 3-month mucosal contours were considered as baseline and 3-month crown-mucosa margins.

\section{Statistical analysis}

Descriptive statistics was computed for all the variables (SPSS Statistics 21, IBM corporation, Somers, NY, USA). The data were described by using mean values, standard deviations (SD), medians, $25^{\text {th }}$ and $75^{\text {th }}$ percentiles. The non-parametric Mann-Whitney-U test was applied to detect differences between the groups because of non-normality of the data. Results of tests with P-values $\leq 0.05$ were considered statistically significant. 


\section{Results}

A total of 28 patients were included for the evaluation of the period from baseline to the 1-year follow-up. Ten patients (6 female, 4 male; mean age: $49.5 \pm 15.3$ years) were included in the group GBR. In this group, $6 \mathrm{Ti}$ and $4 \mathrm{TiZr}$ implants were placed in 8 premolar, 1 canine and 1 incisor site. In the group without GBR, there were 18 patients ( 9 female, 9 male; mean age: $52.2 \pm 14.2$ years). The sites without GBR included 15 premolar and 3 canine gaps with $7 \mathrm{Ti}$ and $11 \mathrm{TiZr}$ implants. A total of 22 patients presented complete recording over a 3-year period. Among those, 9 implants were included in the group GBR and 13 implants in the group without GBR.

From baseline to 3 months (just before abutment connection), horizontal contour change at the level $1 \mathrm{~mm}\left(\mathrm{HCC}_{1 \mathrm{~mm}}\right)$ and $2 \mathrm{~mm}\left(\mathrm{HCC}_{2 \mathrm{~mm}}\right)$ apical to the mucosal margin amounted to $-0.09 \pm 0.43 \mathrm{~mm}$ and $-0.17 \pm 0.50 \mathrm{~mm}$ in the group without GBR, and to $1.00 \pm$ $1.05 \mathrm{~mm}$ and $1.20 \pm 1.48 \mathrm{~mm}$ in the group with simultaneous $\mathrm{GBR}\left(\mathrm{HCC}_{1 \mathrm{~mm}}: \mathrm{P}=0.002\right.$; $\mathrm{HCC}_{2 \mathrm{~mm}}: \mathrm{P}=0.020$ ) (Table 1 ). From baseline to 6 months (immediately after insertion of definitive crown), $\mathrm{HCC}_{1 \mathrm{~mm}}$ and $\mathrm{HCC}_{2 \mathrm{~mm}}$ measured $0.65 \pm 0.74 \mathrm{~mm}$ and $0.55 \pm 0.56 \mathrm{~mm}$ at sites without GBR, and $1.92 \pm 0.87 \mathrm{~mm}$ and $1.76 \pm 0.70 \mathrm{~mm}$ at sites with $\mathrm{GBR}\left(\mathrm{HCC}_{1 \mathrm{~mm}}: \mathrm{P}=\right.$ $\left.0.001 ; \mathrm{HCC}_{2 \mathrm{~mm}}: \mathrm{P}=0.003\right)$. In the period from baseline to the 1-year follow-up, $\mathrm{HCC}_{1 \mathrm{~mm}}$ and $\mathrm{HCC}_{2 \mathrm{~mm}}$ reached $0.81 \pm 0.67 \mathrm{~mm}$ and $0.60 \pm 0.55 \mathrm{~mm}$ in the group without GBR. For the GBR group, the corresponding values amounted to $1.81 \pm 0.86 \mathrm{~mm}$ and to $1.37 \pm 0.62 \mathrm{~mm}$ $\left(\mathrm{HCC}_{1 \mathrm{~mm}}: \mathrm{P}=0.009 ; \mathrm{HCC}_{2 \mathrm{~mm}}: \mathrm{P}=0.020\right)$. When assessing the period from baseline to 3 years, $\mathrm{HCC}_{1 \mathrm{~mm}}$ and $\mathrm{HCC}_{2 \mathrm{~mm}}$ measured $0.63 \pm 0.91 \mathrm{~mm}$ and $0.54 \pm 0.79 \mathrm{~mm}$ in the group without GBR, and $1.77 \pm 1.01 \mathrm{~mm}$ and $1.23 \pm 0.87 \mathrm{~mm}$ in the GBR group $\left(\mathrm{HCC}_{1 \mathrm{~mm}}: \mathrm{P}=\right.$ $0.025 ; \mathrm{HCC}_{2 \mathrm{~mm}}: \mathrm{P}=0.097$ ). The differences between all the variables except $\mathrm{HCC}_{2 \mathrm{~mm}}$ from baseline to 3 years were statistically significant (Table 1, Figure 4).

From baseline to 6 months, mucosal margin moved $0.16 \pm 0.49 \mathrm{~mm}$ in the coronal direction in the group without GBR and $0.82 \pm 0.65 \mathrm{~mm}$ in the group with GBR $(P=0.012)$. In the period from baseline to 1 year, vertical change in mucosal margin amounted to $0.64 \pm$ $0.54 \mathrm{~mm}$ in the group without GBR and to $1.17 \pm 0.53 \mathrm{~mm}$ in the GBR group ( $P=0.027)$. From 6 months (after insertion of definitive crown) to 1 year, the corresponding value measured $0.48 \pm 0.43 \mathrm{~mm}$ in the group without GBR and $0.35 \pm 0.48 \mathrm{~mm}$ in the group with GBR $(P=494)$. From 1 year to 3 years, vertical change in mucosal margin amounted to 0.03 $\pm 0.31 \mathrm{~mm}$ in the group without GBR and to $-0.19 \pm 0.31 \mathrm{~mm}$ in the GBR group $(P=0.110)$ (Table 2). 


\section{Discussion}

In the present study GBR performed simultaneously with implant placement resulted in more gain of buccal soft tissue contour in comparison to implant placement without GBR. The abutment connection increased the buccal contour of the marginal mucosa at the augmented and the non-augmented implant sites. GBR procedure contributed more to the contour gain than did the abutment connection procedure. The augmented and the nonaugmented alveolar ridges exhibited stable peri-implant mucosal contour over a 3-year period.

In clinical studies the most frequently used parameters for the assessment of periimplant mucosal esthetics are vertical levels of the buccal mucosal margin and of the interproximal papillae (Benic et al. 2012b). However, the knowledge remains limited on the overall three-dimensional change of mucosal contours resulting from implant placement and augmentation procedures. To our knowledge, the present investigation was the first one that compared mucosal contour changes at implant sites augmented with GBR to control sites without GBR. Based on the finding of the present study, it may be concluded that GBR procedure positively contributes to the mucosal esthetics. The resulting additional contour increase was stable over a 3-year period.

One of the first clinical studies in this field assessed buccal contour changes after primary bone augmentation and implant placement (Jemt \& Lekholm 2003, 2005). In ten patients with single-tooth maxillary central incisor gaps, primary bone augmentation with autogenous bone blocks was performed 6 months prior to implant placement. Six months after implant placement, abutments and single-implant crowns were installed and followed up for 5 years. For the analysis of mucosal contour changes, the study models were optically scanned and the 3D images were superimposed. At the coronal $2 \mathrm{~mm}$ of mucosa the average increase in the contour after primary bone augmentation amounted to $3.4 \mathrm{~mm}$. One year after bone grafting, prior to abutment connection, the augmented contour decreased to $1.2 \mathrm{~mm}$. At the subsequent crown placement, the gain in the contour measured on average $3.6 \mathrm{~mm}$. In the first year after crown insertion, the contour decreased to a minor extent. Thereafter, a relatively stable average situation was observed during the following 4 years. The investigators concluded that grafting with autogenous bone does not seem to play a major role for building up the coronal part of the mucosal contour. Instead, the abutment connection and the crown insertion affected the mucosal contour more favourably in comparison to the bone grafting. 
Similarly to this study, in the present investigation the contour changes of the coronal 2 $\mathrm{mm}$ of mucosa were assessed. The data from the two trials can, therefore, be compared. The difference in the extent of contour gain after bone augmentation between the studies may be due to different grafting materials. Primary augmentation with autogenous bone blocks allows to predictably increase the horizontal ridge dimension before implant placement (Jensen \& Terheyden 2009, Klein \& Al-Nawas 2011). In the present study, GBR was performed with particulated bone substitute and collagen membrane. It is known that particulated grafting materials in combination with collagen membranes are sub-optimal for the augmentation of non-contained bone defects due to the unfavourable mechanical properties with low resistance to pressure and thus a risk for displacement (Benic et al. 2015, Mir-Mari et al. 2015, Strietzel et al. 2006, Zellin et al. 1995). In situations requiring an increase of the ridge contour, in which the volume stability of the region to be augmented is not provided by the adjacent bone walls, contour-forming augmentations by means of blocks of autogenous bone or rigid non-resorbable membranes are considered to be the treatment of choice (Benic \& Hammerle 2014).

In the previously described investigation of primary augmentation with autogenous bone blocks, the contour reduction in the first year can be explained by the partial resorption of the onlay graft (Jemt \& Lekholm 2005). On the other side, in the present study the gain in ridge contour after GBR with DBBM was maintained over 3 years. The stability of the augmented ridge may be attributed to the low degradation rate of DBBM. A recent clinical trial including 20 patients found DBBM particles unchanged and integrated in the bone 11 years after sinus floor augmentation (Mordenfeld et al. 2010). In a recent randomized clinical trial, peri-implant defects augmented with DBBM and collagen membrane were clinically assessed at re-entry and visualized with CBCT after 5 years (Jung et al. 2015, Jung et al. 2009). Between 6 months and 5 years, the augmented buccal hard tissue exhibited minimal resorption in the apical direction. Based on the findings from these clinical studies, it can be concluded that after the healing, particulated DBBM presents a long-term space making ability.

In the previously discussed study with primary bone augmentation (Jemt \& Lekholm 2005) and in the present trial including sites with and those without GBR, abutment connection procedure always resulted in a horizontal increase of the marginal mucosal contour. This contour gain is attributed to the displacement of the soft tissue from the midcrestal region of the edentulous region, which occurs during abutment connection. It is reasonable to assume that the extent of the contour increase depends on the bucco-oral location of the incision. This variable may explain the discrepancy in the tissue gain after abutment connection and crown insertion between the two studies. Interestingly, the 
horizontal contour gain was maintained over the following years. Moreover, no mucosal recessions in the apical direction were observed among the groups with staged bone augmentation, simultaneous GBR and no GBR.

As far as mucosal stability is concerned, it has to be considered that in the present study all the implants were placed $>4$ months after tooth extraction, thus, reducing the amount of ridge resorption after baseline time-point. In addition, both studies included only single-tooth gaps. Previous studies showed that the presence of adjacent teeth and of the interproximal bone crest at adjacent teeth has a favourable effect on the vertical stability of buccal bone and mucosa at the implant site (Favero et al. 2012, Nisapakultorn et al. 2010).

A recent clinical study assessed the dimensional changes of peri-implant mucosa obtained by implant placement, bone and soft tissue augmentation and prosthetic reconstruction (Schneider et al. 2011). In 16 patients with maxillary incisor single-tooth gaps, implants were placed $>8$ weeks after tooth extraction. Buccal bone was grafted using ePTFE membranes and DBBM. Subsequently, at all the sites soft tissue augmentation was performed by means of connective tissue grafts (CTG). The change in the mucosal contour was assessed through optical scanning and superimposition of the 3D images. Implant placement with GBR using e-PTFE membranes resulted in a gain of labial volume in all cases. The mean contour gain after GBR measured $0.72 \mathrm{~mm}$. On average, the membrane removal and CTG resulted in additional $0.55 \mathrm{~mm}$ of contour increase. From 1 week after crown insertion to the 1-year follow-up, the horizontal contour and the apico-coronal position of the mucosal margin remained stable. The results concerning mucosal change after GBR and following crown insertion from this study are in agreement with the findings of the present investigation. In this context it has, however, to be taken into account that in the two studies different regions-of-interest were applied for the assessment of mucosal changes. Owing to the differences in the mesio-distal gap width and the apico-coronla position of the mucogingival junction among the sites, in the present investigation only the coronal $2 \mathrm{~mm}$ of the mid-buccal mucosa were assessed.

Other clinical studies assessed the dimensions of the buccal bone and/or mucosa at implants placed with GBR immediately after tooth extraction (Benic et al. 2012a, Capelli et al. 2013, Miyamoto \& Obama 2011). In two CBCT studies, the post-extractive resorption of the buccal bone plate was associated with vertical recessions of the mid-buccal mucosal margin (Benic et al. 2012a, Miyamoto \& Obama 2011). Another prospective study optically assessed the mucosal contour changes after immediate implant placement and GBR with and without overbuilding of the buccal bone plate (Capelli et al. 2013). It was concluded that external grafting of the buccal bone lamella is beneficial to maintain the contour of the ridge 
and achieve a successful esthetic result. The differences in the mucosal changes after implant placement between these studies and the present investigation can bet attributed to the different time-point of implant placement after tooth extraction.

Based on the findings of the present study, it can be concluded that despite the unfavourable mechanical properties, GBR with particulated DBBM and collagen membrane has the potential to increase the mucosal contour and positively affect the appearance of the peri-implant mucosa. In addition, abutment connection and crown insertion contribute to the contour augmentation of the marginal peri-implant mucosa.

The small sample size and the statistical analysis without the correction for multiple testing are limitations, which have to be taken into account when interpreting the findings of the present non-randomized study. Another limitation of this study is the fact that 6 out of 28 patients could not be followed-up at 3 years.

Further clinical investigations are needed to assess the long-term 3D changes of periimplant tissues after hard tissue augmentation with different techniques and materials. Ideally, the contour changes should be assessed with reference to the implant placement and to the tooth extraction. Future research should investigate the influence of GBR on the long-term implant survival and success rates. 


\section{Conclusions}

Within the limitations of the present study, it can be concluded that for implants placed in anterior and premolar jaw regions more than 4 months after tooth extraction:

- Implant placement with simultaneous GBR resulted in more gain of buccal soft tissue contour in comparison to implant placement without GBR.

- Abutment connection procedure increased the buccal contour of the marginal mucosa at the augmented and the non-augmented implant sites.

- GBR procedure contributed more to the contour gain than did the abutment connection procedure.

- The augmented and the non-augmented alveolar ridges exhibited stable periimplant mucosal contour over a 3-year period. 


\section{Acknowledgements}

The investigators gratefully acknowledge Dr. Caroline Lustenberger for assistance in analyzing the data. This study was supported by the Clinic of Fixed and Removable Prosthodontics and Dental Material Science, Center of Dental Medicine, University of Zurich, Switzerland. 


\section{Figure legend}

Figure 1. (a) Occlusal and (b) buccal view of single-tooth gap 45 at baseline. Intraoperative (c) occlusal and (d) buccal view of the buccal bone dehiscence immediately after implant placement. Guided bone regeneration with (e) particulated deproteinized bovine-derived bone mineral and (f) collagen membrane. (g) Occlusal view at 3 months, immediately prior to the abutment connection procedure. (h) Buccal view of the porcelain fused-to-metal implant-supported crown at the 3-year follow-up.

Figure 2. Three-dimensional model scans of site 45 with guided bone regeneration: (a) baseline and (b) 1-year follow-up.

Figure 3. Bucco-oral cross-sectional views of the superimposed contours at different time-points: (a) site 45 with guided bone regeneration (GBR) and (b) site 14 without GBR.

Figure 4. Boxplots representing the horizontal contour change (in $\mathrm{mm}$ ) from baseline to 3 months, 6 months, 1 year and 3 years (a) $1 \mathrm{~mm}$ apical to the mucosal margin and (b) $2 \mathrm{~mm}$ apical to the mucosal margin (negative values represent contour reduction) 


\section{Table legend}

Table 1. Results of the horizontal contour change (in $\mathrm{mm}$ ) from baseline to 3 months, 6 months, 1 year and 3 years (negative values represent contour reduction)

Table 2. Results of the vertical change in mid-buccal mucosal margin (in $\mathrm{mm}$ ) from baseline to 3 months, 6 months, 1 year and 3 years (negative values represent mucosal recession) 


\section{References}

Benic, G. I., Gallucci, G. O., Mokti, M., Hammerle, C. H., Weber, H. P. \& Jung, R. E. (2013) Titanium-zirconium narrow-diameter versus titanium regular-diameter implants for anterior and premolar single crowns: 1-year results of a randomized controlled clinical study. Journal of Clinical Periodontology 40: 1052-1061.

Benic, G. I. \& Hammerle, C. H. (2014) Horizontal bone augmentation by means of guided bone regeneration. Periodontology 2000 66: 13-40.

Benic, G. I., Mokti, M., Chen, C. J., Weber, H. P., Hammerle, C. H. \& Gallucci, G. O. (2012a) Dimensions of buccal bone and mucosa at immediately placed implants after 7 years: A clinical and cone beam computed tomography study. Clinical Oral Implants Research 23: 560-566.

Benic, G. I., Thoma, D. S., Munoz, F., Sanz Martin, I., Jung, R. E. \& Hammerle, C. H. (2015) Guided bone regeneration of peri-implant defects with particulated and block xenogenic bone substitutes. Clinical Oral Implants Research: Epub ahead of print.

Benic, G. I., Wolleb, K., Sancho-Puchades, M. \& Hammerle, C. H. (2012b) Systematic review of parameters and methods for the professional assessment of aesthetics in dental implant research. Journal of Clinical Periodontology 39 Suppl 12: 160-192.

Capelli, M., Testori, T., Galli, F., Zuffetti, F., Motroni, A., Weinstein, R. \& Del Fabbro, M. (2013) Implant-buccal plate distance as diagnostic parameter: A prospective cohort study on implant placement in fresh extraction sockets. Journal of Periodontology 84: 1768-1774.

Donos, N., Mardas, N. \& Chadha, V. (2008) Clinical outcomes of implants following lateral bone augmentation: Systematic assessment of available options (barrier membranes, bone grafts, split osteotomy). Journal of Clinical Periodontology 35: 173-202.

Favero, G., Lang, N. P., Favero, G., Leon, I. G., Salata, L. A. \& Botticelli, D. (2012) Role of teeth adjacent to implants installed immediately into extraction sockets: An experimental study in the dog. Clinical Oral Implants Research 23: 402-408.

Hammerle, C. H., Jung, R. E. \& Feloutzis, A. (2002) A systematic review of the survival of implants in bone sites augmented with barrier membranes (guided bone regeneration) in partially edentulous patients. Journal of Clinical Periodontology 29 Suppl 3: 226-231; discussion 232-223.

Jemt, T. \& Lekholm, U. (2003) Measurements of buccal tissue volumes at single-implant restorations after local bone grafting in maxillas: A 3-year clinical prospective study case series. Clinical Implant Dentistry and Related Research 5: 63-70.

Jemt, T. \& Lekholm, U. (2005) Single implants and buccal bone grafts in the anterior maxilla: Measurements of buccal crestal contours in a 6-year prospective clinical study. Clinical Implant Dentistry and Related Research 7: 127-135. 
Jensen, S. S. \& Terheyden, H. (2009) Bone augmentation procedures in localized defects in the alveolar ridge: Clinical results with different bone grafts and bone-substitute materials. International Journal of Oral and Maxillofacial Implants 24 Suppl: 218-236.

Jung, R. E., Benic, G. I., Scherrer, D. \& Hammerle, C. H. (2015) Cone beam computed tomography evaluation of regenerated buccal bone 5 years after simultaneous implant placement and guided bone regeneration procedures-a randomized, controlled clinical trial. Clinical Oral Implants Research 26: 28-34.

Jung, R. E., Halg, G. A., Thoma, D. S. \& Hammerle, C. H. (2009) A randomized, controlled clinical trial to evaluate a new membrane for guided bone regeneration around dental implants. Clinical Oral Implants Research 20: 162-168.

Klein, M. O. \& Al-Nawas, B. (2011) For which clinical indications in dental implantology is the use of bone substitute materials scientifically substantiated? European Journal of Oral Implantology 4: 11-29.

Lutz, R., Neukam, F. W. \& Schmitt, C. M. (2015) Long-term success of implants placed in association with bone augmentation: Soft- and hard-tissue stability. A systematic review Clinical Oral Implants Research: accepted.

Mir-Mari, J., Wui, H., Jung, R. E., Hammerle, C. H. \& Benic, G. I. (2015) Influence of blinded wound closure on the volume stability of different gbr materials: An in vitro cone-beam computed tomographic examination. Clinical Oral Implants Research: Epub ahead of print.

Miyamoto, Y. \& Obama, T. (2011) Dental cone beam computed tomography analyses of postoperative labial bone thickness in maxillary anterior implants: Comparing immediate and delayed implant placement. International Journal of Periodontics and Restorative Dentistry 31: 215-225.

Mordenfeld, A., Hallman, M., Johansson, C. B. \& Albrektsson, T. (2010) Histological and histomorphometrical analyses of biopsies harvested 11 years after maxillary sinus floor augmentation with deproteinized bovine and autogenous bone. Clinical Oral Implants Research 21: 961-970.

Nisapakultorn, K., Suphanantachat, S., Silkosessak, O. \& Rattanamongkolgul, S. (2010) Factors affecting soft tissue level around anterior maxillary single-tooth implants. Clinical Oral Implants Research 21: 662-670.

Schneider, D., Grunder, U., Ender, A., Hammerle, C. H. \& Jung, R. E. (2011) Volume gain and stability of peri-implant tissue following bone and soft tissue augmentation: 1-year results from a prospective cohort study. Clinical Oral Implants Research 22: 28-37.

Strietzel, F. P., Khongkhunthian, P., Khattiya, R., Patchanee, P. \& Reichart, P. A. (2006) Healing pattern of bone defects covered by different membrane types-a histologic study in the porcine mandible. Journal of biomedical materials research. Part B, Applied biomaterials 78: 35-46.

Zellin, G., Gritli-Linde, A. \& Linde, A. (1995) Healing of mandibular defects with different biodegradable and non-biodegradable membranes: An experimental study in rats. Biomaterials 16: 601-609. 
Table 1. Results of the horizontal contour change (in $\mathrm{mm}$ ) from baseline to 3 months, 6 months, 1 year and 3 years (negative values represent contour reduction)

\begin{tabular}{|c|c|c|c|c|c|c|c|c|c|c|}
\hline \multirow[b]{2}{*}{ Parameter } & \multirow[b]{2}{*}{ Period } & \multicolumn{4}{|c|}{ No GBR } & \multicolumn{4}{|c|}{$\overline{G B R}$} & \multirow[b]{2}{*}{ P-value* } \\
\hline & & $\overline{M e a n} \pm$ SD & Median & 25th perc & 75 th perc & $\overline{M e a n} \pm$ SD & Median & 25th perc & 75th perc & \\
\hline $\mathrm{HCC}_{1 \mathrm{~mm}}$ & $B L-3 m$ & $-0.09 \pm 0.43$ & -0.10 & -0.20 & 0 & $1.00 \pm 1.05$ & 0.80 & 0.30 & 1.20 & $0.002^{\dagger}$ \\
\hline $\mathrm{HCC}_{2 \mathrm{~mm}}$ & $B L-3 m$ & $-0.17 \pm 0.50$ & -0.10 & -0.40 & 0 & $1.20 \pm 1.48$ & 0.95 & 0.50 & 1.40 & $0.020+$ \\
\hline $\mathrm{HCC}_{1 \mathrm{~mm}}$ & $\mathrm{BL}-6 \mathrm{~m}$ & $0.65 \pm 0.74$ & 0.75 & 0 & 1.30 & $1.92 \pm 0.87$ & 2.05 & 1.30 & 2.60 & $0.001 \dagger$ \\
\hline $\mathrm{HCC}_{2 \mathrm{~mm}}$ & $\mathrm{BL}-6 \mathrm{~m}$ & $0.55 \pm 0.56$ & 0.60 & 0.20 & 1.00 & $1.76 \pm 0.70$ & 2.00 & 1.30 & 2.30 & $0.003+$ \\
\hline $\mathrm{HCC}_{1 \mathrm{~mm}}$ & $B L-1 y$ & $0.81 \pm 0.67$ & 0.85 & 0.40 & 1.30 & $1.81 \pm 0.86$ & 1.50 & 1.20 & 2.30 & $0.009+$ \\
\hline $\mathrm{HCC}_{2 \mathrm{~mm}}$ & $B L-1 y$ & $0.60 \pm 0.55$ & 0.60 & 0.10 & 1.00 & $1.37 \pm 0.62$ & 1.30 & 0.90 & 1.80 & $0.020+$ \\
\hline $\mathrm{HCC}_{1 \mathrm{~mm}}$ & $B L-3 y$ & $0.63 \pm 0.91$ & 0.50 & 0.10 & 1.30 & $1.77 \pm 1.01$ & 1.60 & 1.00 & 2.20 & $0.025+$ \\
\hline $\mathrm{HCC}_{2 \mathrm{~mm}}$ & $B L-3 y$ & $0.54 \pm 0.79$ & 0.50 & -0.10 & 0.80 & $1.23 \pm 0.87$ & 1.10 & 0.80 & 1.80 & 0.097 \\
\hline $\mathrm{HCC}_{1 \mathrm{~mm}}$ & $3 m-6 m$ & $0.69 \pm 0.68$ & 0.50 & 0.10 & 1.10 & $0.80 \pm 0.90$ & 0.60 & 0.10 & 1.50 & 0.916 \\
\hline $\mathrm{HCC}_{2 \mathrm{~mm}}$ & $3 m-6 m$ & $0.72 \pm 0.56$ & 0.60 & 0.30 & 1.20 & $0.47 \pm 1.38$ & 0.85 & -0.30 & 1.50 & 0.961 \\
\hline $\mathrm{HCC}_{1 \mathrm{~mm}}$ & $6 m-1 y$ & $0.16 \pm 0.23$ & 0.20 & 0 & 0.30 & $-0.11 \pm 0.51$ & -0.10 & -0.30 & 0.30 & 0.160 \\
\hline $\mathrm{HCC}_{2 \mathrm{~mm}}$ & $6 m-1 y$ & $0.05 \pm 0.27$ & 0.10 & -0.10 & 0.20 & $-0.39 \pm 0.50$ & -0.20 & -0.80 & 0 & 0.015 \\
\hline $\mathrm{HCC}_{1 \mathrm{~mm}}$ & $6 m-3 y$ & $0.06 \pm 0.43$ & 0 & -0.10 & 0.40 & $-0.22 \pm 0.69$ & -0.30 & -0.50 & 0.40 & 0.262 \\
\hline $\mathrm{HCC}_{2 \mathrm{~mm}}$ & $6 m-3 y$ & $0.09 \pm 0.52$ & -0.10 & -0.30 & 0.60 & $-0.53 \pm 0.62$ & -0.50 & -0.90 & -0.20 & 0.073 \\
\hline $\mathrm{HCC}_{1 \mathrm{~mm}}$ & $1 y-3 y$ & $-0.07 \pm 0.32$ & 0 & -0.30 & 0.10 & $-0.11 \pm 0.26$ & -0.10 & -0.20 & 0.10 & 0.744 \\
\hline $\mathrm{HCC}_{2 \mathrm{~mm}}$ & $1 y-3 y$ & $0.09 \pm 0.27$ & 0 & -0.10 & 0.30 & $-0.14 \pm 0.28$ & -0.10 & -0.30 & 0 & 0.165 \\
\hline
\end{tabular}


Table 2. Results of the vertical change in mid-buccal mucosal margin (in $\mathrm{mm}$ ) from baseline to 3 months, 6 months, 1 year and 3 years (negative values represent mucosal recession)

\begin{tabular}{|c|c|c|c|c|c|c|c|c|c|}
\hline \multirow[b]{2}{*}{ Period } & \multicolumn{4}{|c|}{ No GBR } & \multicolumn{4}{|c|}{ GBR } & \multirow[b]{2}{*}{ P-value* } \\
\hline & Mean \pm SD & Median & 25th perc & 75th perc & $\overline{M e a n} \pm$ SD & Median & 25th perc & 75th perc & \\
\hline$\overline{B L}-3 m$ & $-0.16 \pm 0.36$ & -0.10 & -0.20 & 0.10 & $0.14 \pm 0.47$ & 0.20 & 0 & 0.30 & $0.0411^{\dagger}$ \\
\hline$B L-6 m$ & $0.16 \pm 0.49$ & 0.20 & -0.20 & 0.60 & $0.82 \pm 0.65$ & 1.00 & 0.20 & 1.30 & $0.012+$ \\
\hline$B L-1 y$ & $0.64 \pm 0.54$ & 0.70 & 0.30 & 1.10 & $1.17 \pm 0.53$ & 1.10 & 1.00 & 1.60 & $0.027+$ \\
\hline$B L-3 y$ & $0.60 \pm 0.67$ & 1.00 & 0 & 1.10 & $1.00 \pm 0.62$ & 1.00 & 0.60 & 1.40 & 0.235 \\
\hline $3 m-6 m$ & $0.31 \pm 0.44$ & 0.20 & 0 & 0.70 & $0.58 \pm 0.46$ & 0.70 & 0.10 & 1.00 & 0.194 \\
\hline $6 m-1 y$ & $0.48 \pm 0.43$ & 0.40 & 0.20 & 0.70 & $0.35 \pm 0.48$ & 0.25 & 0 & 0.60 & 0.494 \\
\hline $6 m-3 y$ & $0.48 \pm 0.50$ & 0.40 & 0.10 & 0.70 & $0.09 \pm 0.60$ & -0.10 & -0.20 & 0 & $0.043+$ \\
\hline $1 y-3 y$ & $0.03 \pm 0.31$ & 0.10 & -0.10 & 0.20 & $-0.19 \pm 0.31$ & -0.20 & -0.30 & -0.10 & 0.110 \\
\hline
\end{tabular}


Figure 1:
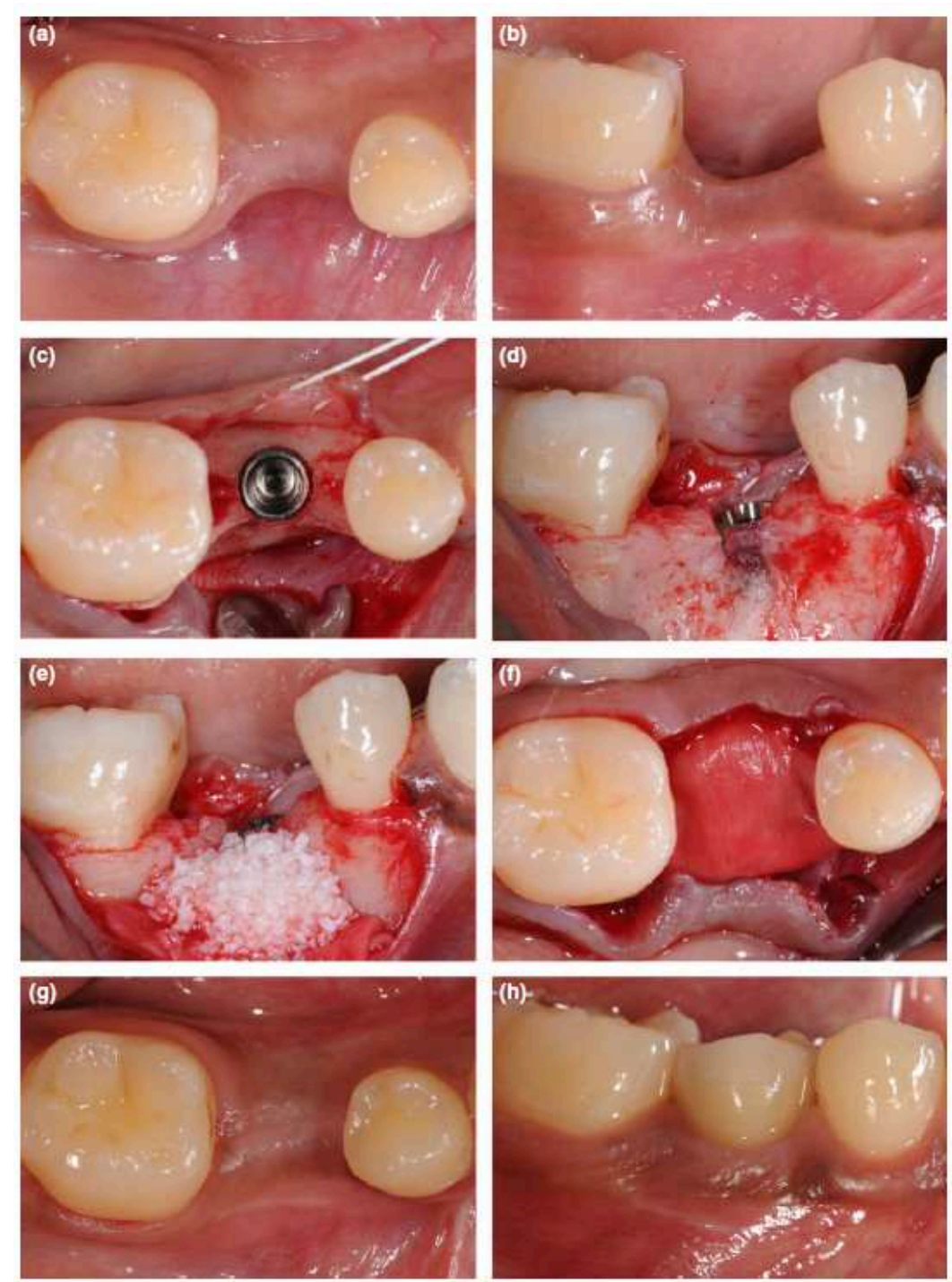

Figure 2
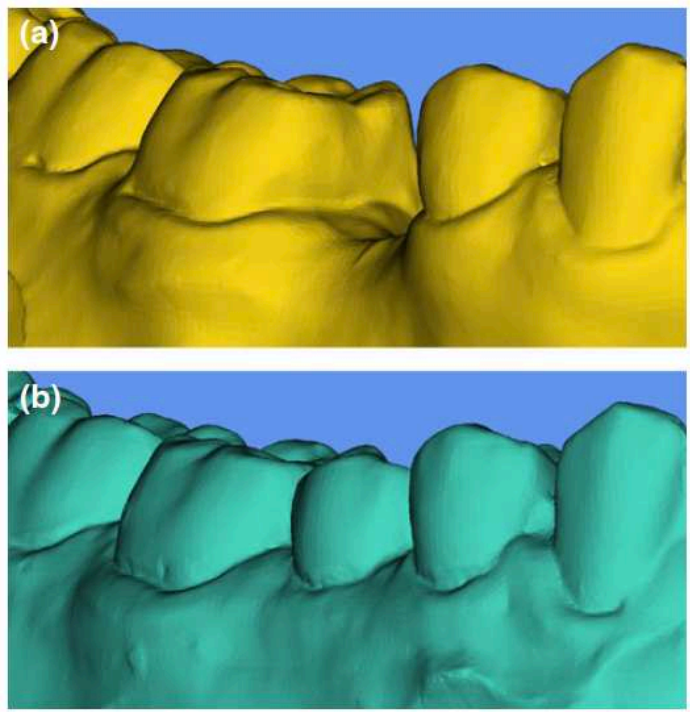
Figure 3
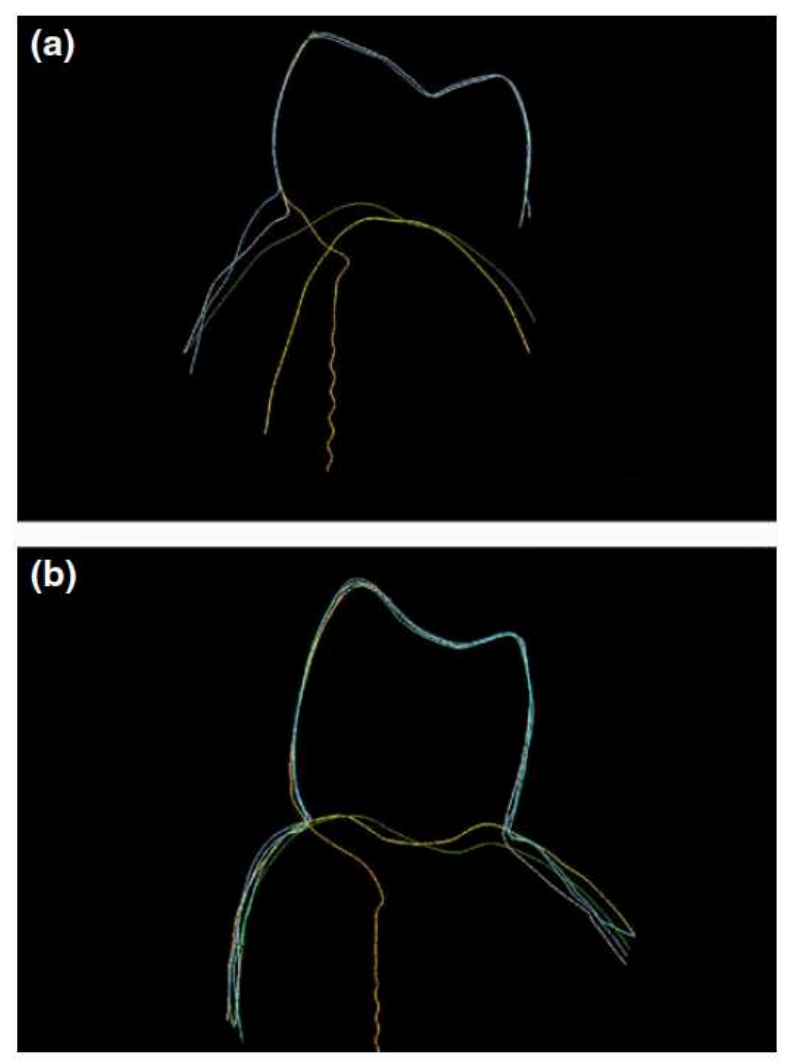

Figure 4a

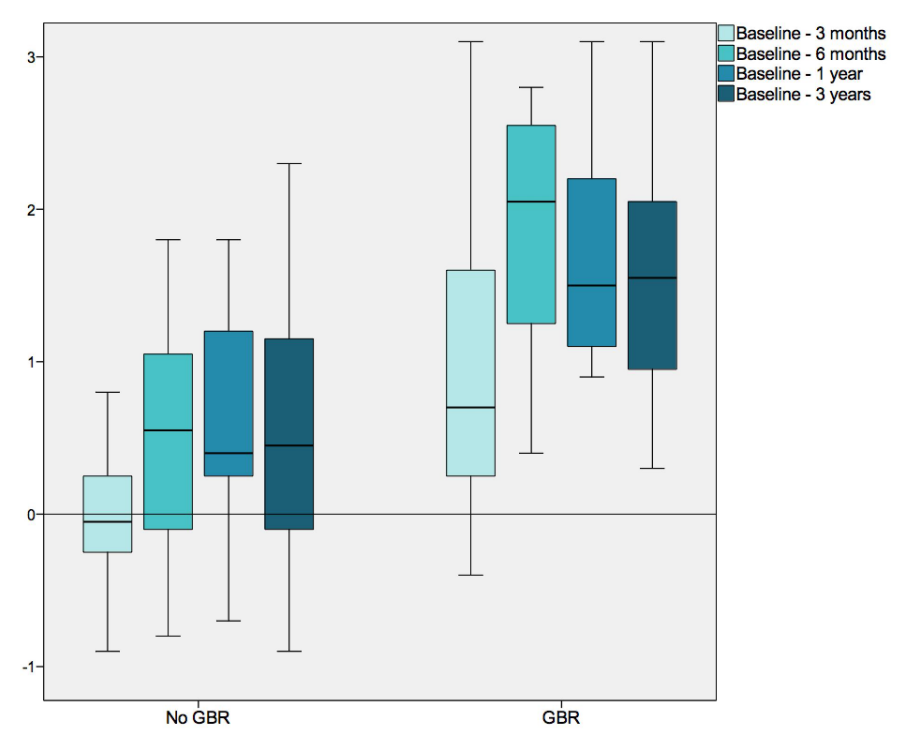


Figure 4b

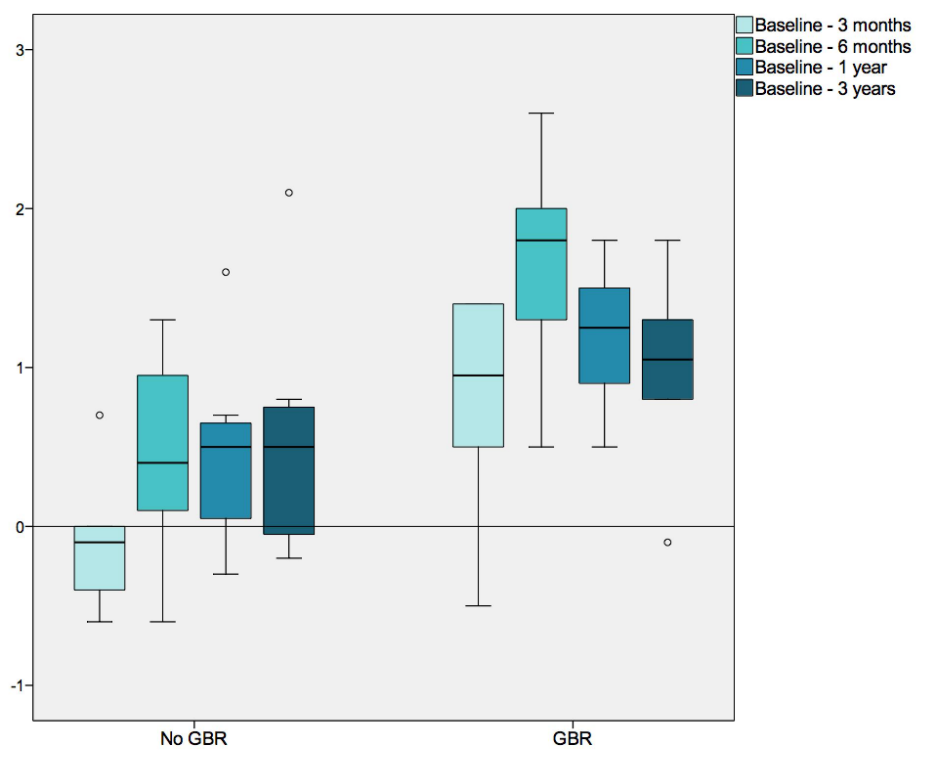

